\title{
A novel slit-integration method of graft urethroplasty in the prevention of ring recurrence: Short-term results of a pilot study
}

\author{
Abdulwahab Akanbi Ajape, Sulyman Alege Kuranga, Hamid Babajide Olanipekun, Taofiq Olayinka Mohammed \\ Division of Urology, Department of Surgery, University of Ilorin and University of Ilorin Teaching Hospital, Ilorin, Nigeria
}

Purpose: To describe and evaluate the efficacy of the slit-integration method in the prevention of ring recurrence after graft substitution urethroplasty.

Materials and Methods: This was a pilot study of selected patients with urethral stricture disease who required urethroplasty from January 2016 to December 2018. Patients were recruited into the study after they granted informed consent about the procedure.

Results: A total of eight patients were involved in this pilot study. The mean age ( \pm standard deviation, SD) of the patients and the mean stricture length $( \pm S D)$ were $44.25( \pm 11.07)$ years and $3.88( \pm 1.25) \mathrm{cm}$, respectively. The peno-bulbar region was the most frequently involved. The majority of the patients, 7 of 8 patients, underwent buccal mucosal graft repair with a mean graft length of $5.88 \mathrm{~cm}$ (range, $4-8 \mathrm{~cm}$ ). There was leak during pericatheter urethrography in one patient. The mean $( \pm \mathrm{SD})$ urethral calibers of the distal and proximal urethral anastomotic sites following urethroplasty were $26.00( \pm 1.85)$ and $25.25( \pm 1.83)$ at 1 week after removal of the urethral catheter stent and $27.75( \pm 0.71)$ and $27.75( \pm 0.71)$ at 12 months postoperatively, respectively. The mean maximum flow rate $( \pm S D)$ at the 6 - and 12-month follow-up was $20.25( \pm 1.83)$ and $21.88( \pm 1.73) \mathrm{mL} / \mathrm{s}$, respectively.

Conclusions: A slit-graft appropriately quilted into the corresponding urethrotomy incisions at the proximal and distal summit of the urethral stricture segments appears to mitigate the occurrence of ring contracture after urethroplasty. A randomized controlled trial of this technique with additional outcome assessment will be required to validate this observation.

Keywords: Pericatheter urethrogram; Ring recurrence; Slit-graft urethroplasty; Urethral calibration; Urethral stricture

This is an Open Access article distributed under the terms of the Creative Commons Attribution Non-Commercial License (http://creativecommons.org/licenses/by-nc/4.0) which permits unrestricted non-commercial use, distribution, and reproduction in any medium, provided the original work is properly cited.

\section{INTRODUCTION}

Urethral stricture disease is a common cause of bladder outflow obstruction. Blunt perineal trauma, urethral catheterization or instrumentation, sexually transmitted diseases, and, more recently, lichen sclerosis are the most frequent causes of urethral stricture disease [1-4].

Open urethroplasty is regarded as the gold standard of treatment for urethral stricture disease and has a high success rate [5]. Although Turner-Warwick's admonition that the urethra is the best substitute for the urethra remains factual [5], urethral reconstruction with excision of the

Received: 8 March, 2019 • Accepted: 15 April, 2019

Corresponding Author: Abdulwahab Akanbi Ajape

Department of Surgery, University of Ilorin, P.M.B. 1515, Ilorin, Nigeria

TEL: +234-803-4570-982, E-mail: ajsnrkudimoh@yahoo.co.uk

ORCID: https://orcid.org/0000-0002-6825-2795 
stricture segment and end-to-end spatulated anastomosis is significantly successful in those with a stricture length of $2 \mathrm{~cm}$ or less [6,7]. Various options have evolved for the reconstruction of those urethral strictures that are of long segments, that are multiple, or that involve the penile urethra, with no one treatment method suitable for all types of strictures [8]. The several options available for a urethra substitute, whether a graft or a flap, have all been associated with varying degrees of complications, including sacculation or diverticulum formation, post-void dribbling, recurrent stricture, and complications related to the donor sites, thus making selection of an appropriate treatment variable among urologists [9]. Experiences with the oral mucosa (buccal, lip, and lingual) in the last decade have reported satisfactory short- and long-term outcomes [3,5,10-14]. Oral mucosa combines the advantages of being readily available, being easy to harvest, being hairless with a thin vascular lamina propria that facilitates graft vascularization, and having a thick epithelial layer rich in elastin that makes it resilient when handling and with low oral/donor site morbidity. Despite the inherent merits that have been credited to oral mucosal substitute, one of the most challenging and significant complications after urethral stricture surgery is stricture recurrence.

The rate of recurrence after use of a buccal mucosa graft (BuMG) for bulbar urethra stricture may be as high as $20 \%$ depending on the definition and measure of outcome, which may include validated questionnaires, uroflowmetry, postvoid residual, urethrography, urethrocystoscopy, calibration, and other measures. Most recurrences occur in the first 2 years after surgery [5,11,14-16]. The most frequent site of recurrence is the proximal or distal anastomotic end [5,11,1416]. It was believed that proximal recurrence might be due to undertreatment of the stricture at the site of recurrence; thus, modification in operative technique may decrease the incidence of failure at these points. Extending the urethral incision $5 \mathrm{~mm}$ into the normal urethra and suturing the proximal and distal anastomotic ends of the buccal graft with six simple interrupted sutures to "tack open" the distal and proximal graft ends in the hopes of decreasing the rate of recurrence has been reported $[16,17]$. Strictures at the proximal or distal graft sites are referred to as "ring recurrences" by Barbagli et al. [18] and are reported to be easily treated with a single direct visual internal urethrotomy (DVIU). Their successful treatment also increases the success rates of BuMG in most series to $94 \%$ to $100 \%$ [17].

Theoretically, incorporating modifications into established surgical techniques of urethroplasty to prevent ring recurrence and other such complications will improve the success rates of the treatment of patients with urethral stricture irrespective of the outcome measures used. We hereby describe and report the outcome of a slit-incorporated graft urethroplasty technique that was introduced to prevent ring recurrence. Our study objective was to describe a novel technique of "Tlorin slit" urethroplasty for anterior urethral stricture and to document the short-term outcome of its use in the management of urethral stricture disease.

\section{MATERIALS AND METHODS}

This was a pilot, prospective, descriptive study of selected patients with urethral stricture disease who required urethroplasty from January 2016 through December 2018. Patients were recruited into the study after they granted informed consent about the procedure.

The biodata and clinical information of the patients was noted; the results of hematological, biochemical, and microbiological investigations and radiological studies (retrograde urethrography [RUG] or RUG combined with voiding cysto-urethrography [VCUG]) were also documented.

\section{Surgical technique}

All patients were routinely evaluated in the outpatient clinic and were only admitted 1 day before surgery, unless otherwise necessary and indicated. The bladder was thoroughly lavaged through the suprapubic cystostomy tube (which was more often present than not) with $0.1 \%$ povidone iodine in normal saline $(10 \mathrm{~mL}$ of $10 \%$ povidone iodine in 1,000 $\mathrm{mL}$ of normal saline) until the effluent was clear.

All patients selected had stricture limited to the penile and distal bulbar to allow for effective treatment with our technical modification (Fig. 1). The anesthesia technique and the initial procedures of exposure were as described earlier [4,16,19-21].

After the initial exposure of the urethra, a ventral sagittal stricturotomy was performed as described by Asopa et al. [22] to expose the urethral lumen and open the stricture segment. Our modification involves dorsal sagittal stricturotomy of the opened urethral stricture segment, with the dorsal urethral incision extending $5 \mathrm{~mm}$ into the normal urethra as a midline incision and an additional 5-mm incision as two sides of an isosceles triangle given an arrowhead-shaped urethral plate in the middle, both proximally and distally (Figs. 2, 3). The urethral plate is then mobilized laterally from the corpus cavernosa to create a wide bed for the BuMG placement.

An appropriate length and width of BuMG is taken 


\section{ICUROLOGY}

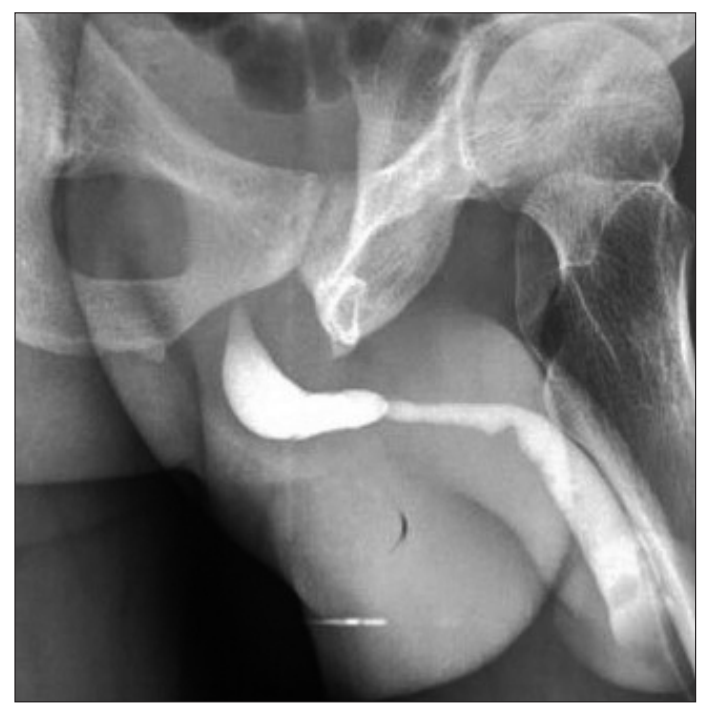

Fig. 1. Retrograde urethrogram (of one of our patients) demonstrating peno-bulbar urethral stricture.

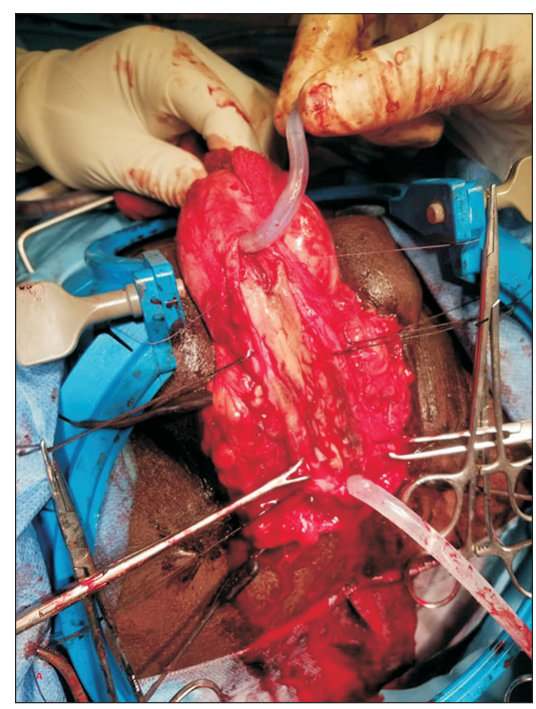

Fig. 2. 'Slit-graft' incorporation on the dorsal urethrotomy graft bed.

from the cheek(s) and defatted, and a corresponding 5-mm midline incision is made on both ends of the graft (Fig. 4). The graft is then quilted and sutured to the urethral mucosa of the stricturotomy site in the usual manner of watertight (5-mm apart), tension-free (2-mm needle entrance from graft and urethra edges), interrupted anastomosis. The ventral sagittal stricturotomy is then closed over a $16-\mathrm{F}$ 2-way silicone Foley catheter inserted into the bladder via the external meatus and spongiorrhapy is done. The perineal wound is then closed with simple interrupted mattress stiches.

The postoperative care entails antibiotics, analgesics, and fluid therapy. The urethral catheter is removed after 3 weeks following a satisfactory pericatheter RUG; this is

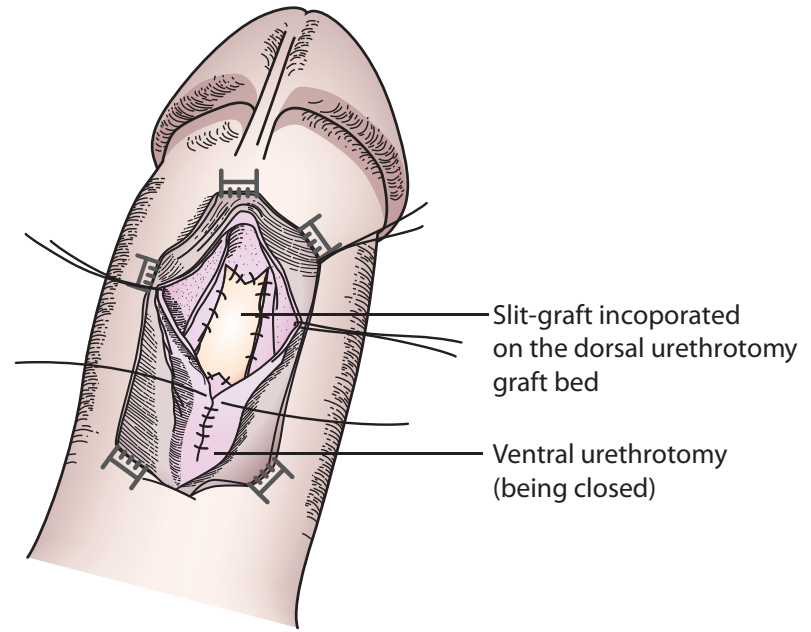

Fig. 3. Schematic representation of 'slit-graft' incorporation anastomosis.

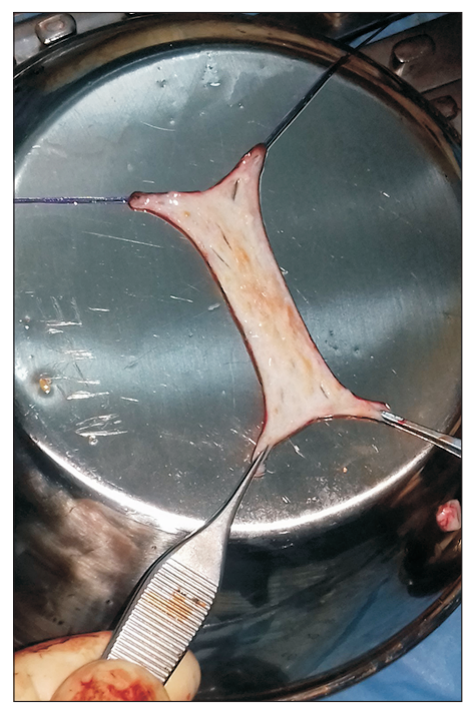

Fig. 4. Harvested 'slit-incorporated' graft (full-thickness skin graft) ready to be used for grafting.

followed by a scheduled urethral calibration at 1 week, 1 month, and every 3 months following surgery.

\section{Urethral calibration}

The urethral calibration aimed to deduce the approximate luminal diameter at both the distal and proximal anastomotic sites. Before the procedure, parenteral antibiotics were administered prophylactically (gentamicin $80 \mathrm{mg}$ ) and 20 $\mathrm{mL}$ of $2 \%$ xylocaine gel was instilled into the urethra. The xylocaine was allowed about 5 minutes to exert a local analgesic effect. A graded insertion of a Clutton bougie set, starting with the largest size (28/32 F), was then undertaken to determine the size that the distal and proximal anastomosis sites admitted; these were taken as the size of the anastomotic rings with which subsequent dimensions were 
compared. Any resistance, after the external meatus had been entered, was presumed to be the distal anastomotic site (this was done side-by-side with the preoperative RUG), and the size of bougie that it admitted was recorded as the size of the distal anastomosis. After the distal site was calibrated, the proximal site of anastomosis was calibrated in a similar manner to document the caliber. At each visit, the International Prostate Symptom Score (IPSS) was evaluated, and uroflowmetry was done 6 and 12 months postoperatively. Only the lower value of the Clutton bougie was recorded so as not to complicate the data analysis. Patients who had completed at least 12 months of follow-up were included for this report.

\section{RESULTS}

A total of eight patients were involved in this pilot study. The patients' mean age ( \pm standard deviation, SD) was $44.25( \pm 11.07)$ years (range, $28-55$ years) and the mean intraoperative stricture length $( \pm \mathrm{SD})$ was $3.88( \pm 1.25) \mathrm{cm}$ (range, 2-6 cm). All patients were male, and seven were married. The peno-bulbar segment of the urethra was the most frequently involved. Only one patient was treated for mid-penile urethral stricture after previously treated hypospadias (Table 1).

The majority of the patients (7 of 8 ) had BuMG urethroplasty with a graft length of $5.88 \mathrm{~cm}$ (range, $4-8 \mathrm{~cm}$ ). Dorsal inlay of the graft was done in six of eight patients, while the remaining two patients had ventral onlay.

There was leak in one of the patients during the routine pericatheter urethrography done at 3 weeks postoperatively, necessitating a delay in urethral catheter removal for another 1 week. The mean $( \pm \mathrm{SD})$ urethral caliber of the distal and proximal urethral repair points was $26.00( \pm 1.85)$ and $25.25( \pm 1.83)$ at 1 week after removal of the urethra catheter stent and $27.75( \pm 0.71)$ and $27.75( \pm 0.71)$ at 12 months postoperatively, respectively. The mean maximum flow rate $(\mathrm{Qmax})( \pm \mathrm{SD})$ at the 6- and 12-month follow-up was 20.25 $( \pm 1.83)$ and $21.88( \pm 1.73) \mathrm{mL} / \mathrm{s}$, respectively.

\section{DISCUSSION}

Interest in the use of a free graft for urethroplasty was reawakened after the publication of several reports from Barbagli et al. [16,18], Elliott et al. [15], Kellner et al. [23], and Mungadi and Ugboko [24]. The many advantages of a BuMG over a skin graft have been enumerated, and this has earned the BuMG its place as the gold standard of the free graft tissues used for urethroplasty [12]. Success rates of $80 \%$ to $100 \%$ have been reported in several series $[17,18]$.

Despite the impressive attributes of BuMG, Barbagli and other authors have also reported incidences of recurrent stricture in the range of $0 \%$ to $20 \%$, with interesting findings of either extensive fibrous tissue of the whole grafted tissue or a fibrous ring stricture at either the proximal and/or the distal anastomotic site [17,18]. The recurrence of a fibrous ring of ten requires further treatment such as DVIU or urethral dilatation, unlike redo urethroplasty for a repeat stricture of the whole grafted tissue [14-16,18,22-24]

In this pilot study, where slit-integration ("Ilorin slit") was incorporated into the graft technique of urethroplasty, the mean age of the male patients studied was $44.25( \pm 11.07)$ years and the mean stricture length was $3.88( \pm 1.25) \mathrm{cm}$; these findings confirmed previous reports that have put the mean age of patients with urethral stricture occurrence in the third and fourth decades of life [6,17], although stricture length varies widely.

All our patients underwent RUG for confirmation of their urethral stricture, and this was adequate for the diagnosis. However, many authors have also advocated the combined use of VCUG, sono-urethrogram, uroflowmetry, and urethro-cystoscopy in the diagnosis of urethral stricture

Table 1. Patient characteristics and treatment outcomes

\begin{tabular}{|c|c|c|c|c|c|c|c|c|c|c|}
\hline $\begin{array}{c}\text { Serial } \\
\text { number }\end{array}$ & Age (y) & Sex & Marital status & Stricture site & IOSL $(\mathrm{cm})$ & Graft tissue & Graft placement & PRUG & $\mathrm{Qmax}_{6}$ & $\mathrm{Qmax}_{12}$ \\
\hline 1 & 49 & Male & Married & Distal bulbar & 4 & BuMG & Dorsal inlay & No leak & 20 & 22 \\
\hline 2 & 51 & Male & Married & Peno-bulbar & 3 & BuMG & Dorsal inlay & No leak & 18 & 24 \\
\hline 3 & 38 & Male & Married & Peno-bulbar & 2 & BuMG & Ventral onlay & Leaked & 21 & 22 \\
\hline 4 & 55 & Male & Married & Peno-bulbar & 4 & FTSG & Dorsal inlay & No leak & 22 & 20 \\
\hline 5 & 28 & Male & Single & Mid-penile & 6 & BuMG & Dorsal inlay & No leak & 19 & 23 \\
\hline 6 & 49 & Male & Married & Distal bulbar & 4 & BuMG & Dorsal inlay & No leak & 23 & 20 \\
\hline 7 & 55 & Male & Married & Peno-bulbar & 3 & BuMG & Ventral onlay & No leak & 21 & 20 \\
\hline 8 & 29 & Male & Married & Peno-bulbar & 5 & BuMG & Dorsal inlay & No leak & 18 & 24 \\
\hline
\end{tabular}

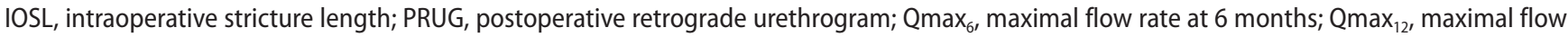
rate at 12 months; BuMG, buccal mucosal graft; FTSG, full-thickness skin graft. 
[25]. Our restriction to RUG alone was not unconnected with the cost, since the majority of our patients paid "out-of-pocket" for the services rendered; however, RUG was adequate for defining the anatomy of the urethral stricture in all our patients. This agrees with the observation of Zimmerman and Santucci [26].

Most of the strictures in this study involved the bulbar urethra (7 of 8 patients), with extension distally to the proximal penile urethra in five cases. Only one patient had a mid-penile stricture after management for hypospadias (Table 1). This finding may be due to the selection of the patients for this pilot study, such that both proximal and distal slit-integration could be adequately coopted into the graft bed. Our findings, however, were similar to those reported by Sawant et al. [17].

Pericatheter RUG at 3 weeks postoperatively is part of the standard of care for post-urethroplasty patients in our practice. All our patients had free contrast flow into the bladder, signifying intact repair, except for one patient who had a leak necessitating delay in urethral catheter stent removal for an additional 1 week.

An objective follow-up protocol is necessary, especially for early detection of recurrent urethral stricture, which constitutes a significant outcome measure following urethroplasty. Unfortunately, however, there is as yet no consensus on the best mode or duration of follow-up after urethroplasty [27]. Both subjective and objective measures have been documented to be used for postoperative assessment of outcome following urethroplasty; these include the IPSS, uroflowmetry, post-void residual volume, RUG, VCUG, urethral calibration, and cystoscopy, among others [28].

The use of the IPSS or uroflowmetry is not appropriate to objectively assess the diameter of the urethral lumen, especially at the anastomotic sites, which was the major consideration in the present study. This is because the symptom scores are subjective and there may be no change in uroflowmetry until the dimension of the urethral lumen is less than 10 to $12 \mathrm{~F}$ [27]. The mean $\mathrm{Qmax}( \pm \mathrm{SD})$ at the 6-month and 12-month follow-up was $20.25( \pm 1.83)$ and 21.88 $( \pm 1.73) \mathrm{mL} / \mathrm{s}$, respectively, in this study. These figures do not signify evidence of obstruction but may not really reflect the caliber of the urethra, especially at the points of anastomosis.

Anatomical changes usually precede impediment of urinary flow; thus, a direct assessment of such anatomical changes will provide a more sensitive, reliable, and reproduceable measure of outcome. Measures of outcome such as the RUG, VCUG, cystoscopy, and urethral calibration were used to assess the anatomical changes; among these methods, cystoscopy has been said to be the most accurate means of detecting stricture recurrence, but this comes with associated cost [27,29,30].

The accuracy of RUG in identifying the size of the anastomotic site after urethroplasty will be subject to several confounding factors, including operator experience, degree of urethral distention, and angle of radiograph projection; furthermore, RUG involves exposure of the patient to irradiation, inconvenience, and cost [29]. For the reasons stated above, RUG was not used to assess the anastomotic sites in the present study.

Urethral calibration has also been proposed as a useful tool for the assessment of outcome after urethroplasty [27]. Whereas interpretation of urethrography has been said to be variable, urethral calibration has been found to provide evidence of anatomical recurrence; thus, its use in this study.

All the patients in the present study had scheduled urethral calibration with a Clutton bougie starting 1 week after removal of the urethral catheter. The mean $( \pm \mathrm{SD})$ urethral calibers of the distal and proximal urethral anastomotic sites were $26.00( \pm 1.85)$ and $25.25( \pm 1.83)$ at 1 week after removal of the urethral catheter stent and $27.75( \pm 0.71)$ and $27.75( \pm 0.71)$ at 12 months postoperatively, respectively (Table 2). Although the preoperative size of the urethral lumen was not documented, it has been proven that the lumen should be less than $16 \mathrm{~F}$ for stricture to be symptomatic in patients [1]. Thus, the mean value of the the urethral diameter (at both the distal and proximal anastomotic sites) at 1 week and 12 months after urethroplasty in the present study does not show evidence of ring recurrence at the anastomotic sites. Further randomized controlled trials involving other measures of outcome will be needed to confirm this observation.

Table 2. Mean value of the Clutton bougie size of the distal and proximal anastomotic sites at various times of follow-up

\begin{tabular}{lccc}
\hline \multirow{2}{*}{$\begin{array}{c}\text { Follow-up } \\
\text { period }\end{array}$} & \multicolumn{2}{c}{ Clutton bougie } & \multirow{2}{*}{ Qmax $(\mathrm{mL} / \mathrm{s})$} \\
\cline { 2 - 3 } & Proximal & Distal & \\
\hline 1st week & $25.25 \pm 1.83$ & $26.00 \pm 1.85$ & \\
1 month & $27.00 \pm 1.51$ & $27.00 \pm 1.51$ & \\
3 months & $27.25 \pm 1.04$ & $27.25 \pm 1.04$ & \\
6 months & $27.25 \pm 1.04$ & $27.25 \pm 1.04$ & $20.25 \pm 1.83$ \\
9 months & $27.75 \pm 0.71$ & $27.75 \pm 0.71$ & \\
12 months & $27.75 \pm 0.71$ & $27.75 \pm 0.71$ & $21.88 \pm 1.73$ \\
\hline
\end{tabular}

Values are presented as mean \pm standard deviation.

Qmax, maximal flow rate. 


\section{CONCLUSIONS}

In conclusion, interposition of a slit-graft appropriately quilted into the corresponding $\mathrm{Y}$ and inverted $\mathrm{Y}$ sliturethrotomy incisions, at the proximal and distal summit of the urethral stricture segments, appears to lessen the occurrence of ring contracture following urethroplasty. A randomized controlled trial of this technique with additional outcome assessment techniques will be required to validate this observation.

\section{CONFLICTS OF INTEREST}

The authors have nothing to disclose.

\section{ACKNOWLEDGMENTS}

The authors thank Mr. Balogun David for the schematic drawing presented in Fig. 3.

\section{REFERENCES}

1. Schlossberg SM. A current overview of the treatment of urethral strictures: etiology, epidemiology, pathophysiology, classification, and principles of repair. In: Schreiter F, Jordan GH. Reconstructive urethral surgery. Heidelberg: Springer; 2006; 59-65.

2. Brandes SB. Epidemiology, etiology, histology, classification, and economic impact of urethral stricture disease. In: Brandes SB. Urethral reconstructive surgery. Totowa: Humana; 2008;5361.

3. Datta B, Rao MP, Acharya RL, Goel N, Saxena V, Trivedi S, et al. Dorsal onlay buccal mucosal graft urethroplasty in long anterior urethral stricture. Int Braz J Urol 2007;33:181-6; discussion 186-7.

4. Abdulwahab AA, Mustapha K, Mbibu NH, Maitama HY, Ojo EO. Perineo-penile degloving exposure in Quartey's urethroplasty: a preliminary report. J Surg Tech Case Rep 2009;1:9-14.

5. Gupta NP, Ansari MS, Dogra PN, Tandon S. Dorsal buccal mucosal graft urethroplasty by a ventral sagittal urethrotomy and minimal-access perineal approach for anterior urethral stricture. BJU Int 2004;93:1287-90.

6. Eltahawy EA, Virasoro R, Schlossberg SM, McCammon KA, Jordan GH. Long-term followup for excision and primary anastomosis for anterior urethral strictures. J Urol 2007;177: 1803-6.

7. Singh O, Gupta SS, Arvind NK. Anterior urethral strictures: a brief review of the current surgical treatment. Urol Int 2011;86:1-10
8. Lee YJ, Kim SW. Current management of urethral stricture. Korean J Urol 2013;54:561-9.

9. Jordan G, Chapple C, Heyns C. Urethral strictures: an Internation Consultation on Urethral Strictures [Internet]. Montreal: Société Internationale d'Urologie; 2012 [cited 2018 Aug]. Available from: https://www.siu-urology.org/themes/web/assets/files/ICUD/pdf/urethral_strictures_2010.pdf.

10. Kröpfl D, Verweyen A. Indications and limits for the use of buccal mucosa for urethral reconstruction. In: Schreiter F, Jordan GH. Reconstructive urethral surgery. Heidelberg: Springer; 2006;195-204.

11. Fichtner J, Filipas D, Fisch M, Hohenfellner R, Thüroff JW. Long-term outcome of ventral buccal mucosa onlay graft urethroplasty for urethral stricture repair. Urology 2004;64:64850.

12. Bhargava S, Chapple CR. Buccal mucosal urethroplasty: is it the new gold standard? BJU Int 2004;93:1191-3.

13. Mungadi IA, Mbibu NH. Current concepts in the management of anterior urethral strictures. Niger J Surg Res 2006;8:103-10.

14. Dubey D, Kumar A, Mandhani A, Srivastava A, Kapoor R, Bhandari M. Buccal mucosal urethroplasty: a versatile technique for all urethral segments. BJU Int 2005;95:625-9.

15. Elliott SP, Metro MJ, McAninch JW. Long-term followup of the ventrally placed buccal mucosa onlay graft in bulbar urethral reconstruction. J Urol 2003;169:1754-7.

16. Barbagli G, Palminteri E, Guazzoni G, Montorsi F, Turini D, Lazzeri M. Bulbar urethroplasty using buccal mucosa grafts placed on the ventral, dorsal or lateral surface of the urethra: are results affected by the surgical technique? J Urol 2005; 174:955-7; discussion 957-8.

17. Sawant AS, Savalia AJ, Pawar PW, Patil SR, Kasat GV, Narwade $S$, et al. An audit of urethroplasty techniques used for managing anterior urethral strictures at a tertiary care teaching institute-what we learned. J Clin Diagn Res 2018;12:PC17-21.

18. Barbagli G, Guazzoni G, Palminteri E, Lazzeri M. Anastomotic fibrous ring as cause of stricture recurrence after bulbar onlay graft urethroplasty. J Urol 2006;176:614-9; discussion 619.

19. Eppley BL, Keating M, Rink R. A buccal mucosal harvesting technique for urethral reconstruction. J Urol 1997;157:126870.

20. Barbagli G, Palminteri E, Guazzoni G, Cavalcanti A. Bulbar urethroplasty using the dorsal approach: current techniques. Int Braz J Urol 2003;29:155-61.

21. Barbagli G, Selli C, Tosto A. Reoperative surgery for recurrent strictures of the penile and bulbous urethra. J Urol 1996; 156:76-7.

22. Asopa HS, Garg M, Singhal GG, Singh L, Asopa J, Nischal A. Dorsal free graft urethroplasty for urethral stricture by ventral sagittal urethrotomy approach. Urology 2001;58:657-9. 
23. Kellner DS, Fracchia JA, Armenakas NA. Ventral onlay buccal mucosal grafts for anterior urethral strictures: long-term followup. J Urol 2004;171(2 Pt 1):726-9.

24. Mungadi IA, Ugboko VI. Oral mucosa grafts for urethral reconstruction. Ann Afr Med 2009;8:203-9.

25. Martins FE, Kulkarni SB, Joshi P, Warner J, Martins N. Management of long-segment and panurethral stricture disease. Adv Urol 2015;2015:853914.

26. Zimmerman WB, Santucci RA. Buccal mucosa urethroplasty for adult urethral strictures. Indian J Urol 2011;27:364-70.

27. Angermeier KW, Rourke KF, Dubey D, Forsyth RJ, Gonzalez CM. SIU/ICUD consultation on urethral strictures: evaluation and follow-up. Urology 2014;83(3 Suppl):S8-17.

28. Meeks JJ, Erickson BA, Granieri MA, Gonzalez CM. Stricture recurrence after urethroplasty: a systematic review. J Urol 2009;182:1266-70.

29. Goonesinghe SK, Hillary CJ, Nicholson TR, Osman NI, Chapple CR. Flexible cystourethroscopy in the follow-up of posturethroplasty patients and characterisation of recurrences. Eur Urol 2015;68:523-9.

30. Liberman D, Pagliara TJ, Pisansky A, Elliott SP. Evaluation of the outcomes after posterior urethroplasty. Arab J Urol 2015;13:53-6. 